\title{
Evaluation of the readiness of a company's IT department for digital business transformation
}

\section{Evgeniy A. Isaev}

Professor, Head of Department of Information Systems and Digital Infrastructure Management National Research University Higher School of Economics Address: 20, Myasnitskaya Street, Moscow, 101000, Russian Federation

E-mail: eisaev@hse.ru

\section{Nina L. Korovkina}

Associate Professor, Department of Information Systems and Digital Infrastructure Management National Research University Higher School of Economics

Address: 20, Myasnitskaya Street, Moscow, 101000, Russian Federation

E-mail: nkorovkina@hse.ru

\section{Maria S. Tabakova}

\section{Graduate of MSc Program}

National Research University Higher School of Economics

Address: 20, Myasnitskaya Street, Moscow, 101000, Russian Federation

E-mail: mstabakova@edu.hse.ru

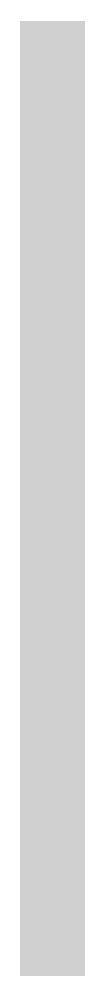

\begin{abstract}
Digital business transformation is a priority for Russian companies in all industries. To develop a company to its full value in the digital environment, it should include an IT department capable of meeting business needs. Evaluation of the current state of the IT department in terms of digital transformation will determine the company's potential for further development.

This article presents a solution to the problem of assessing the IT department's readiness for digital business transformation by developing a quantitative assessment of the maturity level of the IT department processes for meeting the needs of the enterprise. The approach to solving this problem consists in the joint use of models for assessing the digital maturity of the enterprise as a whole and models for assessing the maturity of the IT department processes and herein is the scientific novelty of the results obtained.

At the first stage of the study, based on the analysis of modern information and digital management practices, as well as on the study of approaches to assessing the digital maturity of the enterprise and the processes of the IT department, we developed the requirements for the IT department maturity model of digital business transformation. The study identified the prospects for IT departments that affect its maturity level, developed a model for quantifying each perspective and a model for calculating the minimum level of maturity of the IT department to achieve the expected assessment of the company's digital maturity.

To assess the willingness of IT departments to digitally transform business, a regression equation of IT department maturity level is constructed from the influencing prospects (factors). The results of approbation of the model are presented.
\end{abstract}


Key words: digital transformation, digital business, digitalization, maturity model, digital economy, information technology management.

Citation: Isaev E.A., Korovkina N.L., Tabakova M.S. (2018) Evaluation of the readiness of a company's IT department for digital business transformation. Business Informatics, no. 2 (44), pp. 55-64.

DOI: $10.17323 / 1998-0663.2018 .2 .55 .64$.

\section{Introduction}

I n May 2017, by a Decree of the President of the Russian Federation, the Strategy for the Development of the Information Society in the Russian Federation for 20172030 was approved [1]. To implement this Strategy, the Government of the Russian Federation has developed a program called "The Digital Economy of the Russian Federation" [2], which defines the goals and objectives within the basic directions of the development of the digital economy for the period up to 2024 .

According to Gartner, the digital economy is the creation, consumption and management of the value associated with digital products, services and assets in the organization. The creation of digital value is the result of the creation of new mechanisms for the formation of commodity value complementing and expanding the practices already used in the company. As a result, the company's business goals are linked to the realization of the potential of digital innovation, which leads to the construction of new business models based on digital and information technologies [3].

Constructing the digital economy is closely connected with digital transformation of business. To carry out the digital business successfully, a company should be capable of continuously adapting to volatile environmental conditions. Digital business transformation represents the migration of a company to digital business by changing the organizational culture and implementing new technologies [3].

According to IDC, global costs for digital transformation technologies will grow by $16.8 \%$ annually. The figures will reach 2.1 trillion dollars by 2019 [4]. At the same time, Gartner analysts predict that by 2020 every dollar invested in innovation will have seven dollars to adapt this solution to the business.

In accordance with research carried out by Ernst \& Young, a company's readiness for digital business is $87 \%$ dependent on the development of IT management practices [5]. It should be stressed that the construction of the digital business strategy is based on the capabilities provided by the IT department. The level of its development must satisfy the needs of the business, otherwise "shadow" IT departments appear in the business units, independent of the IT department and its management [6]. As a result, there is a growing likelihood of problems arising not only with the increased IT costs in the company, but also with information security issues and IT management policy requirements.

Thus, to implement initiatives related to digital business, it is necessary to first estimate the ability of the IT department to implement them [7]. To obtain an objective judgment on the activities of the IT department, various models for assessing the maturity of IT processes have been developed $[8,9]$ in accordance with which a determination of the possibilities for achieving the goals set by the IT management processes is made. However, these models do not take into account such aspects as the possibility of integrating IT processes with the processes of other departments of the company and with the processes of partners, as well as cultural features of organizing IT activities and the ability to introduce innovations into business and IT processes. 
On the other hand, there are models for assessing the digital maturity of enterprises in general $[10,11]$ which take into account the company's ability to perform digital transformation but do not allow us to identify problems at the IT level.

\section{Statement of the problem}

An analysis of existing methodologies, standards and best practices (ITIL v.3, ISO-20000, Agile, DevOps, Automating continuous delivery, Bimodal IT, IT4IT) shows that the role and activities of the IT department in business are changing [12-16]. At the same time, it is required that the IT management processes, in the first place, provide the opportunity to implement changes both in the company's business model and in the management processes of the IT department [17].

The need to solve this problem has led to the emergence of models for assessing the digital maturity of companies which allow us to determine the multi-faceted level of maturity of the company in the digital arena. The article considers models of digital maturity assessment of the enterprise developed by consulting companies Forrester and IDC, as well as a model for estimating the digital maturity of a telecommunications enterprise presented by Ericsson.

These models have structures corresponding to standard model CMMI and explain problems of the enterprise in a part of construction of digital business. However, they have the following features that make them insufficient to localize problems and build a plan for the development of companies:

$\downarrow$ models are top-level in the coverage of issues, since they have been originally developed as universal and suitable for companies of any industry;

$\downarrow$ models for assessing the digital maturity of an enterprise by virtue of its general nature do not offer ways to improve the management of an enterprise.

Thus, the mentioned models in their original form do not provide an opportunity to identify problems at the level of the IT department.

As noted, the company's readiness to conduct digital business is $87 \%$ dependent on the development of IT management practices [5]. Based on this judgment, it can be noted that improving the management processes of the IT department can contribute to the development of the overall level of digital maturity of the company. To this end, it is necessary to examine the existing models used to assess the level of maturity of the IT department and determine whether they meet the requirements of the digital business. The models of Capability Maturity Model Integration (CMMI), the COBIT Process Assessment Model (PAM), and the model presented in ISO/IEC 15504 are analyzed [18, 19]. These models are based on checking for the presence or absence of certain characteristics of IT management processes. However, the requirement for flexibility and adaptability of IT processes imposed by digital transformation leads to the need for the highest level of maturity of IT management when management processes are optimized, which in reality happens rarely. Moreover, many of the practices studied are based not on one but on several processes, combining them completely or fragmentarily. Therefore, to assess the maturity of the IT department, it becomes necessary to develop the following requirements for the model:

$\diamond$ the model provides a structured approach to evaluation of digital transformations and is sufficiently comprehensive to cover all aspects of digital transformation;

$\diamond$ the model is detailed in accordance with the management features of the IT department in the digital transformation, while management practices in different areas of development must be taken into account;

the model is an organization-independent process in the IT department;

$\diamond$ the model does not contradict existing mod- 
els for assessing the digital maturity of an organization and the activities of IT departments.

The purpose of the study is to develop a model for quantifying the readiness of the company's IT department for digital business transformation. For this purpose, the following tasks were set and solved:

$\checkmark$ highlighting the prospects (factors) affecting the maturity level of the IT department;

$\checkmark$ development of a model for the quantification of each perspective;

$\checkmark$ development of a model for calculating the minimum level of maturity of the IT department to achieve the expected evaluation of the company's digital maturity;

$\downarrow$ organization of the collection of statistical information for building a model based on correlation-regression analysis;

$\checkmark$ the construction of a regression equation for the level of maturity of IT processes from factors (development prospects);

$\checkmark$ evaluation using the developed model of the level of maturity of the IT department processes and checking the adequacy of the results obtained.

\section{The identification the maturity scale of IT department processes}

To assess the level of maturity of the IT department objectively, a quantitative scale is defined that allows us not only to understand how IT management practices are used, but also to determine how fully they are applied. This will make it possible, in the future, when formulating recommendations for each particular company, to determine which activities will be more likely to develop the level of maturity of the IT department. The scale consists of four levels, which correspond to the levels of digital maturity of the company developed by Forrester. This is due to the following considerations:

- levels adopted in the Forrester model are correlated with the levels of the standardized CMM maturity model;

- the Forrester model is publicly available, which allows it to be used to assess the maturity of the IT department in a DH environment;

- the model is oriented to an enterprise which leads the digital business and sets the direction for the development of the model of the IT department of the company.

Comparison of the quantitative estimates of the maturity levels in the authors' model to maturity levels in the Forrester and CMM models

\begin{tabular}{|c|c|c|c|c|}
\hline $\begin{array}{l}\text { Level in the } \\
\text { authors' } \\
\text { model }\end{array}$ & $\begin{array}{l}\text { Quantitative } \\
\text { valuation } \\
\text { (in points) }\end{array}$ & $\begin{array}{l}\text { Forrester } \\
\text { model } \\
\text { level }\end{array}$ & $\begin{array}{l}\text { CMM } \\
\text { model } \\
\text { level }\end{array}$ & Description of the level of maturity \\
\hline \multirow{2}{*}{ Researchers } & \multirow[b]{2}{*}{1} & \multirow{2}{*}{ Skeptics } & Elementary & \multirow{2}{*}{$\begin{array}{l}\text { The IT department of the company conducts research } \\
\text { on practices used in digital transformation. }\end{array}$} \\
\hline & & & Repeatable & \\
\hline Beginners & 2 & Adopters & Installed & $\begin{array}{l}\text { The IT division of the company actively implements } \\
\text { the changes that form the basis of the company's } \\
\text { digital business. }\end{array}$ \\
\hline Advanced & 3 & Advanced & Managed & $\begin{array}{l}\text { The IT department provides integrated services that } \\
\text { support the end user capabilities (both internal } \\
\text { and external). }\end{array}$ \\
\hline Innovators & 4 & Differentiators & Optimized & $\begin{array}{l}\text { The IT department is constantly experimenting } \\
\text { with new practices and is the driving force behind } \\
\text { the digital transformation. }\end{array}$ \\
\hline
\end{tabular}


Table 1 provides a comparison of the quantitative assessment of the maturity level of the IT department processes to the maturity levels of the Forrester and CMM models.

\section{The identification of the direction of development of the IT department}

Based on the researched practices of IT management, seven determined outlooks of its activity influence the overall success of the company's digital business:

$\downarrow$ Strategy. This direction assesses how management represents the role of IT in the implementation of the digital strategy of the organization as a whole;

$\downarrow$ Organization. In the framework of this direction, changes in communications, culture and knowledge management in the IT departments of the company are assessed;

$\downarrow$ Relationships with users. The IT department, like the business as a whole, should be oriented to the consumer, which primarily implies the provision of services to the business;

$\downarrow$ Partnership. Digital business and the digital economy are built not only within a specific company, but also within the framework of a common ecosystem where companies form alliances and other partnerships. Therefore, the processes of the IT department should be organized in such a way as to make the simple integration with the partners of the company;

$\downarrow$ Operations. The IT department will not be flexible in providing services to the business unless it can dynamically reconfigure its internal processes for the most effective solution of internal tasks;

$\downarrow$ Technologies. To increase the speed of service delivery to the business and reduce the probability of errors in the provision of services, there is a necessity to automate the functions of the IT department everywhere - both in the processes of supporting current services and in the deployment and integration of changes; $\downarrow$ Innovation. The IT department of the company must constantly be in search of new solutions that will increase the flexibility of the provision of services to the business.

\section{Identification of the attributes of the maturity of management of the IT department}

Based on a study of the practices used by the IT department in the process of digital transformation, the analysis of the model's maturity attributes developed by Ericsson [11], and the principles specified in COBIT 5 [9], a list of attributes was defined for quantifying each of the prospect IT departments that meet certain levels of maturity. To formalize the attributes of the model, a system for encoding them is proposed. The attribute code is formed as follows: the designation of the evaluation perspective ( $\mathrm{S}$ - strategy, Or - Organization, $\mathrm{R}$ - Relationships with users, $\mathrm{P}$ - Partnership, Op - Operations, $\mathrm{T}$ Technology, I - Innovations), quantitative level of maturity (1 - Researchers, 2 - Beginners, 3 Advanced, 4 - Innovators), through the point the ordinal number of the attribute.

\section{The development of a model for quantifying the prospects of the IT department}

The model is developed in the form of a questionnaire and consists of 29 questions on seven perspectives $^{1}$ : Strategy (4), Organization (5) User Interaction (3), Partnership (4), Operating activities (4), Technology (6), Innovations (3). There are several answers for each of the questions offered. Only one answer can be selected. The possible answers are represented by the attributes of each perspective. A total of 102 attributes have been developed.

The development of model questions was based on the fact that they should not be redundant to the maturity model, but they should cover all the attributes of maturity. This model

\footnotetext{
${ }^{1}$ Number of questions for each perspective is stated in parentheses
} 
provides an estimation of the average state of the IT department processes in seven areas of development (prospects).

On the basis of this model, a questionnaire was developed, which, in addition to the questionnaire, contains fields for filling in the name of the organization, the respondent's position, and the company's industry affiliation. Since the full questionnaire is too voluminous, a small fragment is given as an example for its presentation in the article (Table 2).
6. The formation of a model for calculating the minimal maturity level of the IT department to achieve the expected evaluation of the company's digital maturity

Based on Ernst \& Young's conclusion that the company's readiness to conduct digital business is $87 \%$ dependent on the development of IT management practices [5], we assume that the weight (importance) of the

Fragment of the questionnaire

Table 2.

Questions on the perspective of "Relations with users"

\section{Possible answers}

\section{Checked maturity} attributes
Seore in points

Question R1. Is the Service-Oriented Approach implemented when providing IT services to users?

\begin{tabular}{l|c|c}
\hline When providing IT services, the service approach is not used & - & 0 \\
\hline $\begin{array}{l}\text { Client-oriented granting of services is chosen as one of the directions for which } \\
\text { the development of the IT department will be carried out. }\end{array}$ & R1.1 & 1 \\
\hline Initiatives are being introduced to provide a service approach to the work of IT. & R2.1 & 2 \\
\hline The services provided by the IT department can be estimated in monetary terms. & R3.1 & 3 \\
\hline $\begin{array}{l}\text { The catalog of services provided by the IT department is constantly updated and } \\
\text { changed depending on the supported digital products and capabilities. }\end{array}$ & R4.1 & 4
\end{tabular}

Question R2. Are there any means in the process of improving the activities of the IT department that contribute to the self-service of users of IT services?

\begin{tabular}{l|c|c}
\hline Service of users is carried out only through the support service. & - & 0 \\
\hline For users of IT services, basic self-service tools are available. & R1.2 & 1 \\
\hline $\begin{array}{l}\text { New ways of interaction with users are being introduced, feedback tools are } \\
\text { being developed with users of IT services. }\end{array}$ & R2.2 & 2 \\
\hline $\begin{array}{l}\text { Users work with the IT department not only in the support service mode, but } \\
\text { also have access to self-configuration capabilities of services. }\end{array}$ & R3.2 & 3 \\
\hline $\begin{array}{l}\text { Digital tools allow users to completely independently configure the IT services } \\
\text { they need to carry out their professional activities. }\end{array}$ & R4.2 & 4
\end{tabular}

Question R3. Do you work with feedback from IT services users?

\begin{tabular}{l|l|c}
\hline Feedback from users of IT services is absent. & R1.3 & 1 \\
\hline Baseline information is collected from users of IT services. & R2.3 & 2 \\
\hline $\begin{array}{l}\text { Data on users' work is collected through all channels of interaction with them } \\
\text { and used to improve the service. }\end{array}$ & R3.3 & 3 \\
\hline $\begin{array}{l}\text { Feedback from users of IT services is constantly analyzed and used to provide } \\
\text { new services to each user. }\end{array}$ & R4.3 & 4 \\
\hline
\end{tabular}


IT department's maturity assessment in assessing the digital maturity of the company is 0.87 . Thus, in order for the IT department to ensure the level of digital maturity of the company obtained as a result of the Forrester model estimation, it is necessary that the estimation of its digital maturity level is not lower than the minimum estimate obtained by the formula (1). In this case, estimates for all other possible business areas (concomitant) are accepted as maximum, equal to 4 according to the adopted scale (Table 1). Associated evaluations are external to the IT department and do not take into account aspects of its activities [20].

The minimum level of development of the IT department which is necessary to meet its business expectations is calculated by the formula:

$$
r_{1}=\frac{r_{c}-(1-k) \cdot r_{\max }}{k}
$$

where $r_{1}$ - the minimum maturity level of the IT department to achieve the expected evaluation of the company's digital maturity;

$r_{c}$ - expected estimation of digital maturity of the company by Forrester model;

$k$ - the importance (weight) of the maturity assessment of the IT department $(k=0.87)$;

$r_{\max }$ - the maximum estimation of the associated estimates $\left(r_{\max }=4\right)$.

\section{Data collection for the development of a quantitative model of the IT department's readiness for digital transformation}

Data collection for developing a quantitative model of the IT department's readiness for digital transformation is a very laborious task. This is because the concept of digital technologies remains rather blurred and often in companies there is no understanding of whether they use digital technologies or information technologies. Therefore, at the first stage, it was necessary to identify those companies that are implementing digital technologies in the business models, such as augmented reality (for example, aircraft building), Internet of things (transport company), machine training (telecommunications company), and others. The survey involved companies from different industries, subject to roughly equal ratio of the total number of employees in the company to the number of employees in the IT department and the mandatory use of digital technology in conducting business. A total of 22 companies from four sectors participated in the study: tourism, banking, telecommunications and industry.

Representatives of the selected companies were asked to fill in two questionnaires prepared based on the authors' model and the Forrester model. It was possible to fill in one questionnaire with several employees responsible for the various activities of the IT department.

Based on the questionnaire for the Forrester model, the expected evaluation of the company's digital maturity is determined for each company under study and the minimum maturity level of the IT department is calculated using the formula (1) to achieve the expected estimate of the company's digital maturity (a number of dependent variables are constructed). For each company under study, by conducting a survey on the authors' questionnaire for each perspective (factor), a quantitative estimate was calculated, calculated as the average value of the respondents' marked attributes (rows of independent variables were constructed).

\section{The regression dependence of the level of maturity of IT department processes on the prospects}

The survey of companies provided the collection of statistical information for constructing a regression model for the quantitative assessment of the IT department's readiness for digital transformation. As shown by the correlation analysis of the collected data, the relationship between the estimates for individual perspectives of the IT department's activities takes place, but is minor and can be disregarded (Table 3). 


\section{Correlation matrix}

\begin{tabular}{|c|c|c|c|c|c|c|c|c|}
\hline & 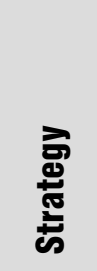 & 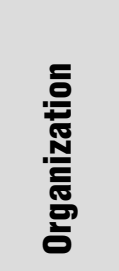 & 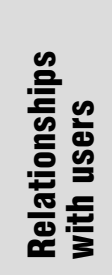 & 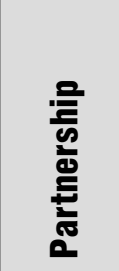 & 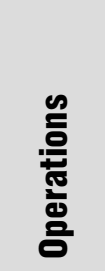 & 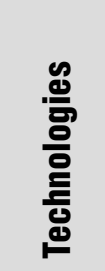 & $\begin{array}{l}\text { 号 } \\
\text { 壱 } \\
\text { 兽 }\end{array}$ & 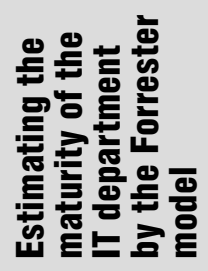 \\
\hline Strategy & 1 & & & & & & & \\
\hline Organization & 0.392 & 1 & & & & & & \\
\hline Relationships with users & 0.424 & 0.322 & 1 & & & & & \\
\hline Partnership & 0.232 & -0.255 & -0.203 & 1 & & & & \\
\hline Operations & 0.331 & 0.437 & 0.379 & -0.106 & 1 & & & \\
\hline Technologies & 0.424 & 0.106 & 0.336 & 0.376 & 0.467 & 1 & & \\
\hline Innovations & 0.334 & 0.130 & 0.451 & 0.234 & 0.142 & 0.138 & 1 & \\
\hline $\begin{array}{l}\text { Estimating the maturity } \\
\text { of the IT department by } \\
\text { the Forrester model }\end{array}$ & 0.774 & 0.579 & 0.726 & 0.638 & 0.682 & 0.707 & 0.826 & 1 \\
\hline
\end{tabular}

Analysis of the correlation matrix has shown that the assessment of the level of maturity of the IT department calculated by the Forrester model has a high positive correlation with the factors "Strategy," "Relationships with users," "Technologies" and "Innovations" (range of values from 0.7 to 0.82 ). The average positive connection strength occurs with the factors "Organization," "Partnership" and "Operations" (range of values $0.57-0.68$ ). This conclusion led to the construction of regression dependence of the maturity of the IT department processes from the prospects. The analysis of regression statistics confirmed the presence of a linear relationship between the indicators (the coefficient of determination of multiple regression is 0.99). The calculation of Fisher's criterion showed that the model is appropriate at a significance level of $1 \%$.The quantitative model so developed allows us to assess the level of maturity of the IT department based on its internal features:

$$
\begin{gathered}
r_{2}=-0.572+0.189 \cdot S+0.279 \cdot O r+ \\
+0.210 \cdot R+0.163 P+0.086 \cdot O p+ \\
+0.503 \cdot T+0.131 \cdot I
\end{gathered}
$$

where $r_{2}$ - maturity of the IT department in a digital transformation environment;

$S$ - assessment of the perspective "Strategy";

$\mathrm{Or}$ - assessment of the perspective "Organization";

$R$ - assessment of the perspective "Relationships with users";

$P$ - assessment of the perspective "Partnership";

$O p$ - assessment of the perspective "Operations";

$T$ - assessment of the perspective of "Technology";

$I$ - assessment of the perspective "Innovations". 
The resulting regression equation can be used to calculate the level of maturity of the IT department when conducting benchmarking studies of companies conducting digital business, and also to compare them and determine the level of development of the company under study against the background of the general picture of the market.

\section{Approbation of the developed model}

To test the developed regression model, the digital maturity of IT departments of ten companies conducting digital business and not participating in the first survey was evaluated. The results are shown in Table 4. As a percentage, the deviation of the IT department's maturity estimate calculated using the regression model (formula 2) from the estimate calculated on the basis of the Forrester model estimate does not exceed $11 \%$, which is permissible within the framework of the study.

The telecommunications company showed the highest level of maturity in the management of the IT division, while the second place was taken by the commercial bank. This is an expected result, as these areas are most eager to invest and develop the information and digital business potential.

\section{Conclusion}

The developed model can be used in the following situations:

$\downarrow$ the company's management makes a decision to develop business models related to entering the digital market;

$\downarrow$ the company that conducts digital business understands the presence of bottlenecks in the use of digital technologies and aims to localize problems;

$\downarrow$ the appearance of competitors with higher performance indicators;

$\downarrow$ consumers of digital products (services) complain about the quality of the products (services) provided.

The proposed model has been successfully tested in ten companies to assess the readiness of their IT departments for digital transformation. In addition, for the two companies (one of which is the leading retailer in the e-commerce market in Russia and the CIS), recom-

The results of the maturity assessment of IT departments of companies

\begin{tabular}{c|c|c|c|c} 
Company & $\begin{array}{c}\text { Estimating the maturity } \\
\text { of the IT department } \\
\text { by formula (2) }\end{array}$ & $\begin{array}{c}\text { Estimating the maturity } \\
\text { of the IT department by } \\
\text { the Forrester model }\end{array}$ & $\begin{array}{c}\text { Absolute } \\
\text { deviation }\end{array}$ & $\begin{array}{c}\text { Relative } \\
\text { deviation }\end{array}$ \\
\hline Company 1 & 2.79 & 3.14 & 0.35 & $11 \%$ \\
\hline Company 2 & 2.52 & 2.82 & 0.30 & $11 \%$ \\
\hline Company 3 & 2.76 & 3.07 & 0.31 & $10 \%$ \\
\hline Company 4 & 2.52 & 2.78 & 0.25 & $9 \%$ \\
\hline Company 5 & 2.58 & 2.83 & 0.25 & $9 \%$ \\
\hline Company 6 & 1.73 & 1.90 & 0.18 & $9 \%$ \\
\hline Company 7 & 1.84 & 2.02 & 0.17 & $9 \%$ \\
\hline Company 8 & 2.73 & 2.99 & 0.26 & $9 \%$ \\
\hline Company 9 & 2.42 & 2.65 & 0.23 & $9 \%$ \\
\hline Company 10 & 2.93 & 3.47 & 0.38 & $11 \%$ \\
\hline
\end{tabular}


mendations were developed on the directions of their development which were approved by the management of IT departments.

Further development of the model presented is possible in the following areas:

$\checkmark$ improving the maturity levels gradation in the developed model; $\checkmark$ expanding the list of model attributes and corresponding questionnaire questions for the most accurate and diligent evaluation of IT management processes;

$\checkmark$ the development of a procedure to assess the readiness of the IT department for digital transformation.

\section{References}

1. Strategiya razvitiya informatsionnogo obshchestva v Rossiyskoy Federatsii na 2017-2030 gody [Strategy for the development of the Information Society in the Russian Federation for 2017-2030]. Decree of the President of the Russian Federation, 9 May 2017, No. 203 (in Russian).

2. Programma "Tsifrovaya ekonomika Rossiyskoy Federatsii" [Program "The digital economy of the Russian Federation]. Order of the Government of the Russian Federation, 28 July 2017, No. 1632-r (in Russian).

3. Gartner (2016) Gartner reveals top predictions for IT organizations and users in 2017 and beyond. Available at: https://www.gartner.com/newsroom/id/3482117 (accessed 13 April 2018).

4. IDC (2016) IDC sees the dawn of the DX economy and the Rise of the digital-native enterprise. Available at: https://www.idc.com/getdoc.jsp?containerId=prUS41888916 (accessed 13 April 2018).

5. Velema T., Harmsen F., Wiedenhofer A. (2016) Born to be digital: how leading CIOs are preparing for a digital transformation. Performance, vol. 6, no. 1, pp. 27-33.

6. Kontzer T. (2014) Shadow IT's growing footprint. Available at: http://www.cioinsight.com/security/ slideshows/shadow-its-growing-footprint.html (accessed 17 May 2018).

7. Digital Bridge Partners Inc. (2016) CIO digital business maturity model and transformation roadmap. New York, Digital Bridge Partners Inc.

8. Chaudhary M., Chopra A. (2017) CMMI for development: Implementation guide. New York, Apress.

9. ISACA (2013) COBIT Process Assessment Model (PAM): Using COBIT 5. Rolling Meadows, ISACA.

10. Gill M., VanBoskirk S. (2016) The Digital Maturity Model 4.O. Benchmarks: Digital business transformation playbook. Available at: https://forrester.nitro-digital.com/pdf/Forrester-s\%20Digital\%20Maturity\%20 Model\%204.0.pdf (accessed 13 April 2018).

11. Valdez-de-Leon O. (2016) A digital maturity model for telecommunications service providers. Technology Innovation Management Review, vol. 6, no. 8, pp. 19-32.

12. The Open Group (2015) The Open Group IT4IT reference architecture. Berkshire: The Open Group.

13. Larman C., Vodde B. (2016) Practices for scaling lean \& agile development. New York: Addison-Wesley Professional.

14. Mesaglio M., Mingay S. (2014) Bimodal IT: How to be digitally agile without making a mess. Available at: https://www.gartner.com/doc/2798217/bimodal-it-digitally-agile-making (accessed 13 April 2018).

15. Kim G., Behr K., Spafford G. (2013) The Phoenix project: A novel about IT, DevOps, and helping your business win. Portland: IT Revolution Press.

16. Narayan S. (2015) Agile IT organization design: For digital transformation and continuous delivery. New York: Addison-Wesley Professional.

17. Hu Y. (2016) How are CIO's addressing the need for digital transformation? Hitachi Data Systems Community, pp. 50-52.

18. ISACA (2012) COBIT 5: A business framework for the governance and management of enterprise IT. Rolling Meadows: ISACA.

19. Chrissis M.B., Konrad M., Sandy S. (2013) CMMI: Guidelines for process integration and product improvement. London: Addison-Wesley Professional.

20. Rohan M. (2014) It is difficult to talk of value when you cannot measure the value you are delivering. Available at: http://www.business-standard.com/article/management/it-is-difficult-to-talk-of-value-when-you-cannot-measure-the-value-you-are-delivering-rohan-murty-114121400510_1.html (accessed 17 May 2018). 